\title{
Trauma encefálico em bezerros: quatro relatos de casos
}

Ana Clara Sarzedas Ribeiro[a]", Laís Resende Paulino ${ }^{[a]}$, José Augusto Bastos Afonso $0^{[b]}$, Nivaldo de Azevedo Costa ${ }^{[b]}$, Carla Lopes de Mendonça ${ }^{[b]}$, Rodolfo José Cavalcanti Souto ${ }^{[b]}$, Nivan Antônio Alves da Silva ${ }^{[b]}$, Maria Isabel de Souza ${ }^{[b]}$, Luiz Teles Coutinho[b], Jobson Filipe de Paula Cajueiro[b]

\footnotetext{
[a] Programa de Residência em Sanidade de Ruminantes, Clínica de Bovinos, Universidade Federal Rural de Pernambuco (UFRPE), Garanhuns, PE, Brasil

[b] Clínica de Bovinos, Universidade Federal Rural de Pernambuco (UFRPE), Garanhuns, PE, Brasil
}

*Autor correspondente

e-mail: ac_sarzedas@id.uff.br

\section{Resumo}

Lesões traumáticas do encéfalo são menos frequentes em bovinos do que em outras espécies e podem derivar de trauma externo direto, estiramento ou flexão violentos da cabeça ou pescoço e migração de larvas de parasitos. Os sinais clínicos variam em função do local e extensão da lesão. 0 presente trabalho descreve quatro casos de trauma encefálico em bezerros atendidos na Clínica de Bovinos, Campus Garanhuns, Universidade Federal Rural de Pernambuco, entre os anos 2004 e 2017. Os animais, três machos e uma fêmea, entre dois meses e um ano de idade, possuíam histórico de doença neurológica de evolução superaguda. Ao exame físico, constatou-se: decúbito esternal ou dificuldade em manter-se em estação, mucosas congestas, desidratação de 8 a 12\%, taquicardia, anorexia e hipomotilidade ruminal. Em um caso havia secreção sanguinolenta nas narinas. No exame neurológico, evidenciou-se: depressão, pressão da cabeça contra objetos, andar em círculo, movimentos de pedalagem, ausência de reflexo olfatório, redução ou ausência de acuidade visual, estrabismo, ptose palpebral e auricular, redução da sensibilidade da face, córnea e mucosa nasal, torção lateral de cabeça, giro ortotônico do pescoço, disfagia, redução do tônus da língua, aumento do tônus da mandíbula. Constatou-se ainda ataxia, paresia flácida, redução ou ausência de reflexos sensitivos e motores de pescoço, tronco e membros e redução de reflexos de cauda e ânus. Três bovinos foram tratados com dexametasona (0,1 a 0,2 mg/Kg) e vitamina B1 (10 a $20 \mathrm{mg} / \mathrm{Kg}$ ), com início do tratamento no $1^{\circ}, 2^{\circ}$ e $6^{\circ}$ dia após o aparecimento dos sinais clínicos, não apresentando resposta satisfatória. Dois animais vieram a óbito e dois foram eutanasiados, sendo submetidos à necropsia. As lesões encontradas no exame anatomopatológico foram: discreto edema subcutâneo em regiões variadas da calota craniana, hematoma submeníngeo acompanhado de áreas deprimidas no telencéfalo, edema, congestão e 
hemorragias sulfusivas também no telencéfalo. Tais achados caracterizam a ocorrência de trauma contuso do crânio, resultando em perda de integridade vascular e hemorragia do parênquima encefálico e meninges. Os sinais clínicos apresentados pelos animais são compatíveis com lesões localizadas no cérebro, cerebelo, tronco encefálico e sistema vestibular. A formação de hematoma subdural, com aumento de volume progressivo, comprime o cérebro adjacente à lesão, resultando em aumento da pressão intracraniana, edema cerebral, áreas de isquemia e, ainda, compressão das demais estruturas encefálicas, justificando a sintomatologia neurológica apresentada. Mesmo nos casos em que o protocolo de tratamento foi instituído pouco tempo após o surgimento dos sinais clínicos, não houve sucesso devido à gravidade das lesões. Diante disto, o trauma encefálico deve ser considerado como diagnóstico diferencial de doenças neurológicas de evolução superaguda ou aguda em bovinos, destacando a importância do exame neurológico e os achados de necropsia para o diagnóstico definitivo nestes casos. 